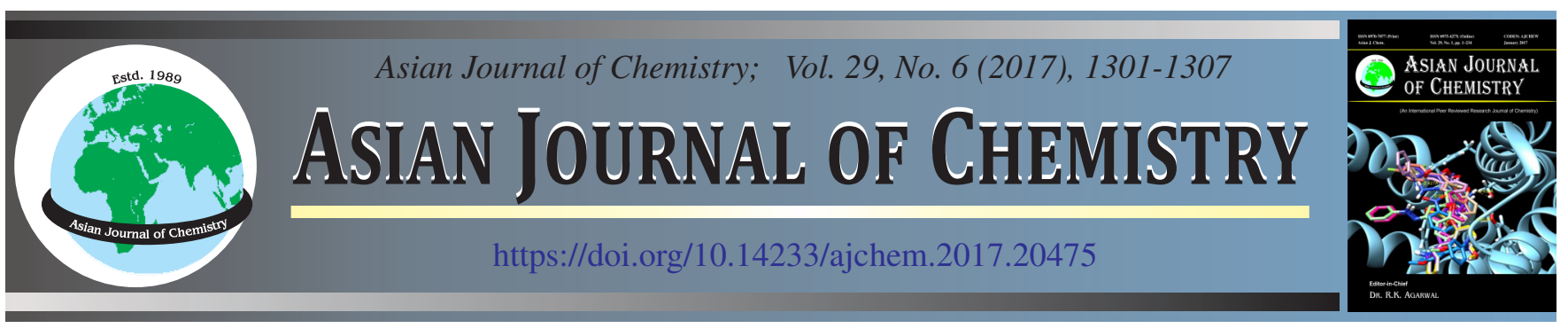

\title{
Comparison of Elemental Analysis for Different Kind of Papers by Using Energy Dispersive X-Ray Spectrometer
}

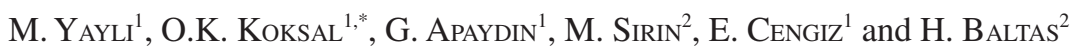

${ }^{1}$ Department of Physics, Faculty of Sciences, Karadeniz Technical University, 61080 Trabzon, Turkey

${ }^{2}$ Department of Physics, Faculty of Arts and Sciences, Recep Tayyip Erdogan University, 53100 Rize, Turkey

*Corresponding author: Fax: +90 462 3253197; Tel: +90 462377 3573; E-mail: okoksal@ktu.edu.tr

Received: 26 December 2016;

Accepted: 17 February 2017;

Published online: 10 April 2017;

AJC-18343

\begin{abstract}
In this study, comparative analyses of different 27 brand papers widely used in Turkey as ashes of paper in the form of pellets. The white paper and photocopied paper have been analyzed by using the energy dispersive X-ray spectrometer system. The analyses indicated the elemental concentration values for specimens in parts per million. Besides, Pearson correlation relations were calculated with statistical package for the social sciences. When the obtained values in this study are examined carefully, it is evident that the changing content of paper is considerable. The aim of this study is to compare the original paper with photocopied paper and ashes of paper in terms of elemental concentration. It is believed that the obtained results in this study will contribute to the data base on the paper elemental characterization.
\end{abstract}

Keywords: EDXRF, Paper analysis, Elemental analysis.

\section{INTRODUCTION}

Since the beginning of history, our ancestors have made use of different types of materials, including stone, ivory, metals, textiles, etc to draw signs and share information. Although many materials have been employed during the history of human kind, the most commonly used graphic supplies have been papyrus, parchment and paper [1]. When one speaks about paper, the first thing that comes to mind is that it is for carrying information, not for wrapping and packaging [2]. Nowadays, paper is the most common information carrier as it used to be. Pulp is diluted to at least $99 \%$ with water and a mineral filler and water soluble substances such as optical brighteners and polyvinyl alcohol are added in the production of paper. Silicates, sulphates, carbonates, oxides and sulphides are used as mineral fillers depending on the paper application [3,4].

Rozic et al. [2] have made elemental analyses for ashes of office paper by using EDXRF spectrometry. Artificial aging processes in modern paper have been researched with X-ray spectrometry technique by Manso et al. [5]. Lartigue et al. [6] have analyzed some of cigarette paper with the help of EDXRF. The elemental characterization from papyrus to paper has been investigated with X-ray fluorescence spectrometry by Manso et al. [7]. Manso et al. [8] have compared the elemental content between modern and ancient paper by EDXRF. The characterization of paper which belongs to $18^{\text {th }}$ and $19^{\text {th }}$ century documents has been examined using X-ray fluorescence spectrometry by Manso et al. [9] and Van Es et al. [10] have surveyed the discrimination of document paper by XRF, LAICP-MS and IRMS using multivariate statistical technique.

The raw material of paper is cellulose since it is made from trees. However, various elements are added by the manufacturer. The most important stuff in all of the additives is the polyelectrolytes which make better the fineness and filler retention, provide the drainage of the paper suspension more efficient and at the same time add specific qualifications [11]. For the improvement of surface properties of paper, picture colour and quality, polymers soluble in water predominantly starch or soluble cellulose products are added in paper mass in a separate process, or paper mass is coated with these substances. The pigment in coating layer could be clay platelets, calcium carbonate, titanium dioxide, calcium sulphate, talc, or synthetic pigments [4]. Thus, the paper has become a doped. The main problem starts at this stage. There is no standard for paper additives used in the production process. In addition to this, paper manufacturers keep the proportions of additives used as a secret. This situation makes the paper manufacturing process an enigma for the users. The lack of standardization in papermaking has led us to perform this study. This present study will contribute to the database on paper's elemental characterization and provide efficient paper identification. 
The office paper was analyzed by using energy dispersive $\mathrm{X}$-ray fluorescence technique (EDXRF) in this study. The main advantage of this technique is that it is non-destructive, which makes it a convenient tool for elemental analysis of paper. The application of this technique preserves the integrity of the paper and allows the characterization of each type of paper $[12,13]$. The aim of this study is to compare the white paper, photocopied paper and ashes of paper in terms of elemental concentration.

\section{EXPERIMENTAL}

Twenty seven different brands of paper weighing $80 \mathrm{~g} / \mathrm{m}^{2}$ and paper size A4 $210 \times 297 \mathrm{~mm}$ in each three groups as original, photocopied paper and ashes of paper, were collected and then analyzed with the energy dispersive X-ray fluorescence (EDXRF) system.

Sampling: One A4 sheet of each paper sample was used for all the analytical procedures. Twenty-seven different brands of white paper did not undergo any processing. Photocopy paper was obtained by pulling double-sided copies of the original text. Samples were cut diagonally from top left to bottom right for white paper as shown in Fig. 1 and for photocopied paper specimens were obtained by cutting in the way as shown in Fig. 2. Each circle has a diameter of $37 \mathrm{~mm}$. Due to the heterogeneity of the paper and in order to evaluate the variation in composition within a sheet, three areas of the paper were sampled. Ashes of paper are prepared as the paper was combusted on the glass and finally all of the samples were shaped as pellets as shown in Fig. 3.

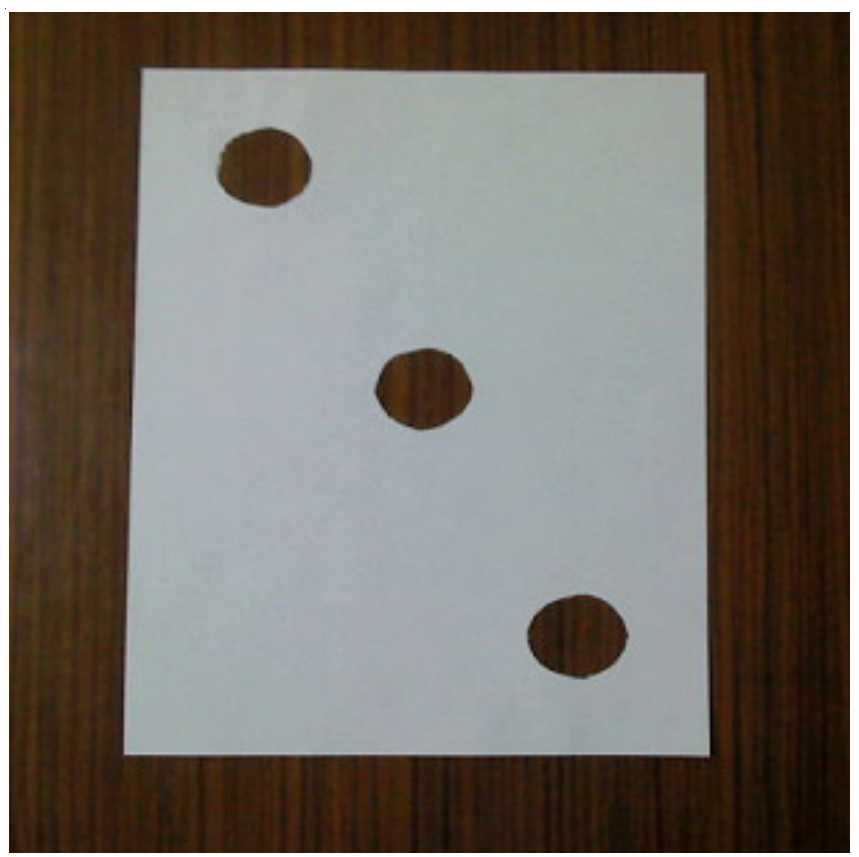

Fig. 1. Locations of white paper samples were cut

X-ray fluorescence instrumentation and method: An EDXRF spectrometer (Epsilon5, PANalytical, Almelo, the Netherlands) was used to determine the metal content of paper sample. This system is a three-dimensional geometry and optical polarized anode X-ray tube $600 \mathrm{Gd}, 100 \mathrm{kV}$ generator for up to 15 high resolution of secondary and polarized target consists of PAN-32 detector. The XY axis is able to receive up

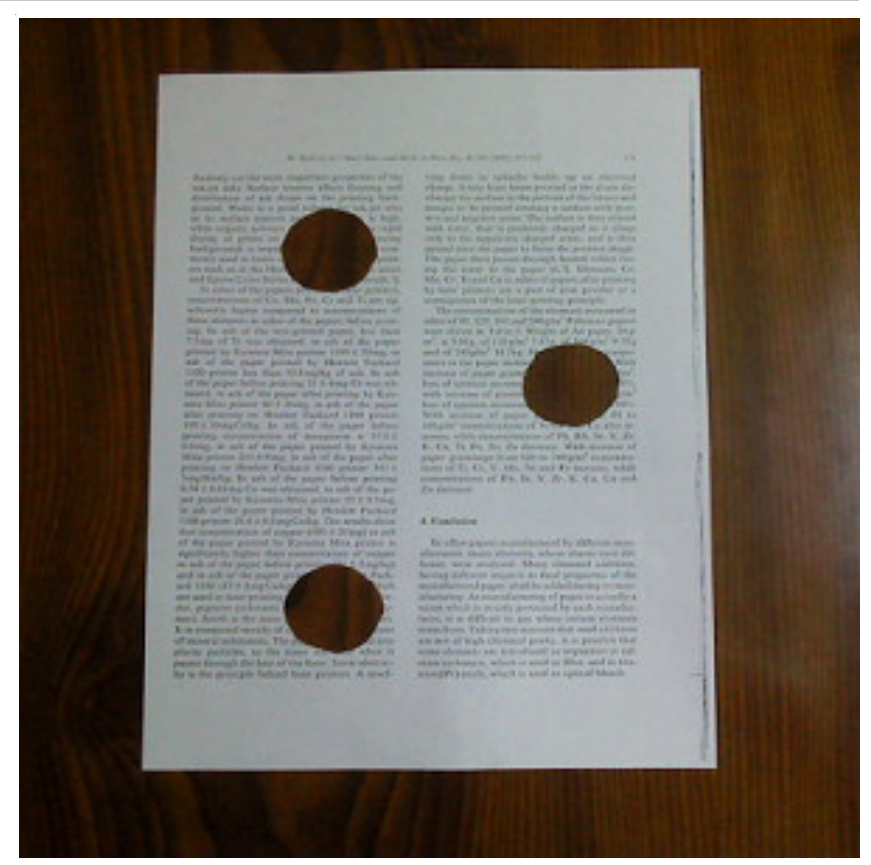

Fig. 2. Locations of photocopied paper samples were cut

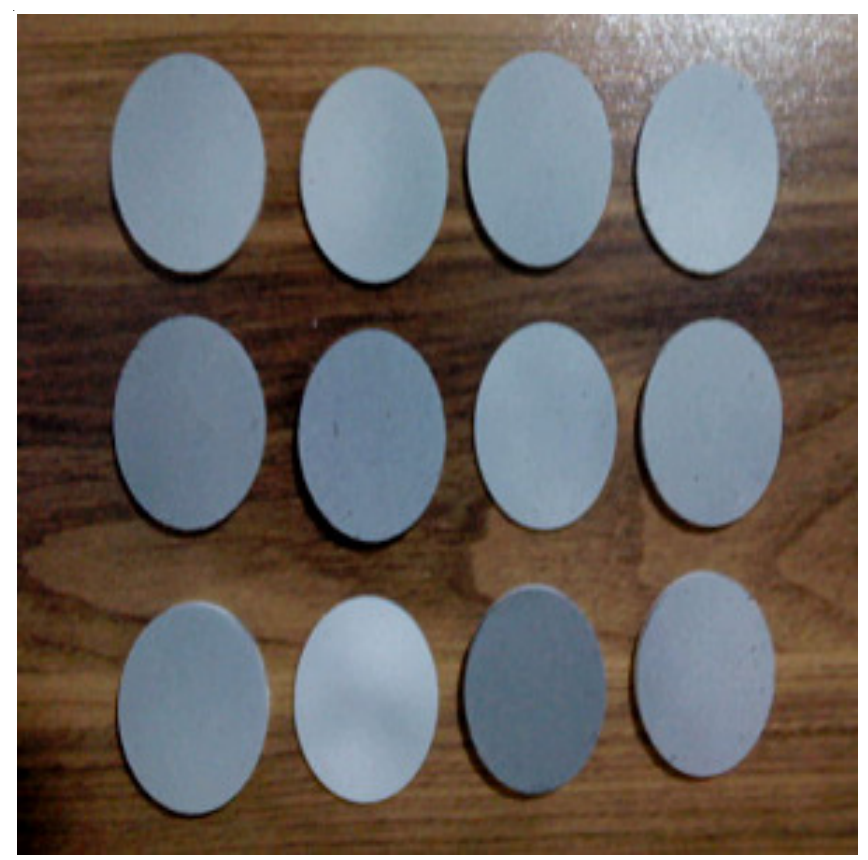

Fig. 3. Pellet forms of ashes of paper

to 133 samples with sample changer, measurements can be carried out for solid and liquid samples in a vacuum and helium environment. Secondary sources of EDXRF system used in this study are $\mathrm{Al}_{2} \mathrm{O}_{3}, \mathrm{CeO}_{2}, \mathrm{Ag}, \mathrm{Mo}, \mathrm{Zr}, \mathrm{Ge}, \mathrm{Fe}$, Ti and $\mathrm{Al}$ in pellet form as same thicknesses at the different densities. The thickness and densities of pellets of these secondary sources are shown in Table-1. Each sample was analyzed by EDXRF system; the averages of the three measured values of the same paper were calculated.

Statistically evaluation of data: The statistical data evaluation was done with statistical package for social sciences (SPSS) program and Pearson correlation was used to examine the properties of the correlations among the elements. 


\begin{tabular}{ccc}
\hline \multicolumn{3}{c}{ TABLE-1 } \\
\multicolumn{3}{c}{ SECONDARY SOURCES OF PRESENT SYSTEM } \\
USED IN PELLET FORM AS SAME THICKNESS \\
AT DIFFERENT DENSITIES \\
\hline Secondary source & Thickness $(\mu \mathrm{m})$ & Density $\left(\mathrm{g} / \mathrm{cm}^{3}\right)$ \\
\hline $\mathrm{Al}_{2} \mathrm{O}_{3}$ & 600 & 3.94 \\
$\mathrm{CeO}_{2}$ & 600 & 6.84 \\
$\mathrm{Ag}$ & 600 & 10.5 \\
$\mathrm{Mo}$ & 600 & 10.2 \\
$\mathrm{Zr}$ & 600 & 6.49 \\
$\mathrm{Ge}$ & 600 & 5.35 \\
$\mathrm{Fe}$ & 600 & 7.86 \\
$\mathrm{Ti}$ & 600 & 4.52 \\
$\mathrm{Al}$ & 600 & 2.70 \\
\hline
\end{tabular}

\section{RESULTS AND DISCUSSION}

The elemental contents of $\mathrm{Mg}, \mathrm{Al}, \mathrm{Si}, \mathrm{S}, \mathrm{Cl}, \mathrm{K}, \mathrm{Sc}, \mathrm{Ti}, \mathrm{Mn}$ and $\mathrm{Fe}$ are illustrated in Table-2, Tables 3 and 4 for white, photocopied and ashes of paper, respectively. When looking at these tables, it is seen that the highest concentrations of elements in the white, photocopied and ashes of paper are $\mathrm{Al}, \mathrm{Si}, \mathrm{S} ; \mathrm{Mg}, \mathrm{Al}, \mathrm{Si}$; Si, Fe, Al; respectively. As, Br, Zr, I, Pr, $\mathrm{Yb}, \mathrm{Hf}, \mathrm{Au}$ and $\mathrm{Pu}$ are not illustrated in any table due to very low elemental concentrations. These elements are thought to originate from the measurement system and the sampling process. Besides, each of the spectra for white, photocopied and ashes of paper is plotted in Figs. 4-6. If the correlation level is positive, the concentration values of the two elements are directly proportional. When the correlation level is zero, there is no relationship between the concentration values of the two elements. If there is negative correlation level among

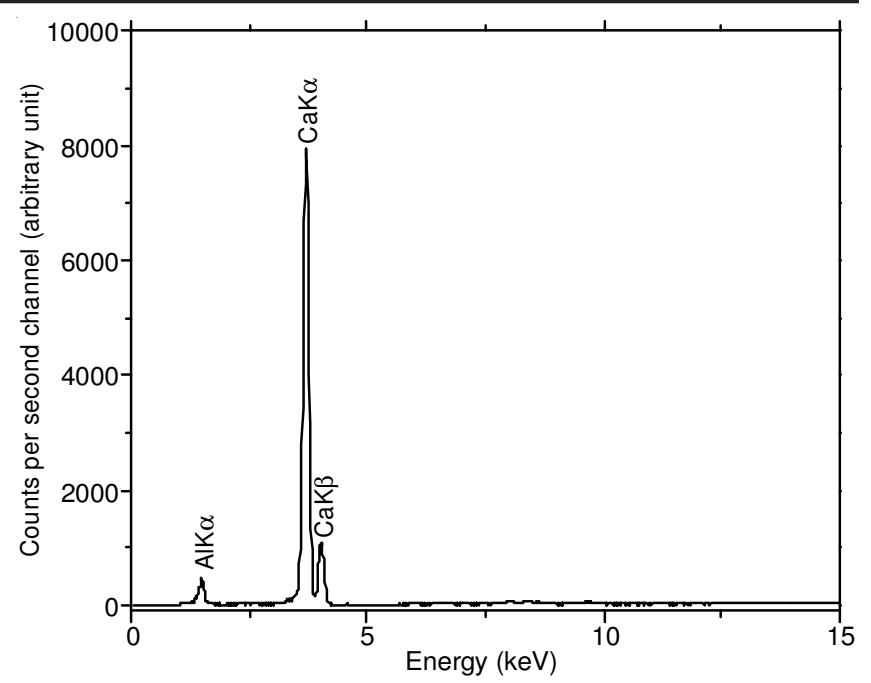

Fig. 4. EDXRF spectra of white paper

any two elements, the concentration values of the elements are inversely proportional. The correlation levels and sensitivities for each set of paper are shown in Tables 5-7.

Table-5 showed that there is a high positive linear relationship between $\mathrm{S}-\mathrm{Al}, \mathrm{Ca}-\mathrm{Al}, \mathrm{Fe}-\mathrm{Mn}$ and $\mathrm{Pb}-\mathrm{Al}$ and it is seen that there is a very high positive linear relationship between $\mathrm{Zn}$ and $\mathrm{Fe}$ for white papers. If considering Table-6, a high linear correlation was detected between Fe-Mn and ZnMn. A statistically significant high positive linear relationship was determined between $\mathrm{Zn}$-Fe for photocopied paper. When considered Table-7, there were no data about correlational relationship at very high level for ashes of paper.

TABLE-2

ELEMENTAL CONCENTRATIONS OF TWENTY SEVEN WHITE PAPERS IN PARTS PER MILLION

\begin{tabular}{|c|c|c|c|c|c|c|c|c|c|c|c|c|c|c|}
\hline & $\mathrm{Al}$ & $\mathrm{Si}$ & $\mathrm{S}$ & $\mathrm{Cl}$ & $\mathrm{K}$ & $\mathrm{Ca}$ & $\mathrm{Ti}$ & $\mathrm{Mn}$ & $\mathrm{Fe}$ & $\mathrm{Co}$ & $\mathrm{Ni}$ & $\mathrm{Cu}$ & $\mathrm{Zn}$ & $\mathrm{Sr}$ \\
\hline W1 & 7120 & - & 764 & 495 & - & 201943 & - & 52 & 166 & - & 70 & 26 & 16 & 21 \\
\hline W2 & 7547 & - & 999 & 1021 & 593 & 183350 & - & 10 & 95 & - & 53 & 26 & 21 & - \\
\hline W3 & 10597 & 2730 & 1003 & 1253 & 1135 & 204233 & - & 12 & 103 & - & 42 & 23 & 18 & 11 \\
\hline W4 & 59737 & 2970 & 3376 & 2273 & 707 & 403303 & - & 61 & 191 & - & - & 40 & 14 & 28 \\
\hline W5 & 47010 & - & 4228 & 1169 & 543 & 340483 & - & 8 & 96 & - & - & 32 & 23 & - \\
\hline W6 & 7977 & - & 946 & 922 & 623 & 175513 & - & 11 & 130 & - & 60 & 25 & 23 & - \\
\hline W7 & 11580 & 4160 & 1883 & 1699 & - & 197180 & 56 & 18 & 331 & - & - & 26 & 17 & 20 \\
\hline W8 & 9073 & 2640 & 1181 & 2630 & - & 163020 & - & 17 & 175 & - & 38 & 22 & 27 & 104 \\
\hline W9 & 10323 & 6603 & 849 & 691 & - & 201233 & 167 & 27 & 283 & - & 159 & 22 & 25 & 36 \\
\hline W10 & 8980 & 5540 & 869 & 1143 & 519 & 153450 & 238 & 95 & 8850 & 18 & - & 30 & 60 & 48 \\
\hline W11 & 13250 & 3550 & 2610 & 4410 & - & 201233 & 79 & 21 & 321 & - & - & 20 & 19 & 19 \\
\hline W12 & 41540 & 30190 & 5565 & 2025 & 1824 & 153647 & - & 17 & 153 & - & - & 33 & 30 & 132 \\
\hline W13 & 12753 & 3870 & 2138 & 5783 & - & 189893 & 74 & 10 & 348 & - & - & 26 & 22 & 19 \\
\hline W14 & 9377 & 2540 & 1118 & 519 & 573 & 200883 & - & 10 & 93 & - & - & 25 & 22 & 14 \\
\hline W15 & 8307 & 3580 & 1693 & 1412 & - & 183533 & - & 11 & 168 & - & - & 24 & 15 & 12 \\
\hline W17 & 7260 & - & 1013 & 375 & - & 167960 & - & 10 & 99 & - & - & 69 & 17 & 9 \\
\hline W18 & 10740 & 3693 & 1324 & 1334 & - & 209487 & - & 15 & 173 & - & 97 & 28 & 23 & 19 \\
\hline W19 & 10133 & 4197 & 1269 & 924 & - & 196590 & - & 18 & 205 & - & - & 27 & 18 & 17 \\
\hline W20 & 9560 & - & 1342 & 1227 & - & 193213 & - & 8 & 76 & - & - & 26 & 23 & - \\
\hline W21 & 7640 & 2785 & 1969 & 613 & 516 & 166793 & - & 13 & 98 & - & 143 & 27 & 17 & 96 \\
\hline W22 & 12610 & 3707 & 1919 & 4087 & 701 & 199747 & 88 & 15 & 340 & - & - & 22 & 17 & 24 \\
\hline W23 & 11090 & - & 1399 & 1114 & - & 209017 & - & 8 & 77 & - & 77 & 24 & 19 & - \\
\hline W24 & 8810 & 3645 & 1710 & 1161 & - & 183583 & - & 16 & 117 & - & 54 & 25 & 23 & 161 \\
\hline W25 & 11223 & 3573 & 2247 & 5693 & - & 174640 & - & 8 & 126 & - & - & 27 & 18 & - \\
\hline W26 & 8660 & 3055 & 1635 & 834 & - & 180173 & - & 13 & 183 & - & 24 & 23 & 24 & 134 \\
\hline W27 & 5837 & 2140 & 1009 & 1614 & 424 & 126717 & - & 27 & 119 & - & - & 33 & 20 & 31 \\
\hline
\end{tabular}


TABLE-3

ELEMENTAL CONCENTRATIONS OF TWENTY SEVEN PHOTOCOPIED PAPERS IN PARTS PER MILLION

\begin{tabular}{|c|c|c|c|c|c|c|c|c|c|c|c|c|c|c|}
\hline & $\mathrm{Al}$ & $\mathrm{Si}$ & $S$ & $\mathrm{Cl}$ & $\mathrm{K}$ & $\mathrm{Ca}$ & $\mathrm{Ti}$ & $\mathrm{Mn}$ & $\mathrm{Fe}$ & Co & $\mathrm{Ni}$ & $\mathrm{Cu}$ & $\mathrm{Zn}$ & $\mathrm{Sr}$ \\
\hline P1 & 7507 & 1291 & 904 & 754 & 698 & 165257 & 175 & 187 & 18837 & 38 & - & 22 & 86 & 23 \\
\hline $\mathrm{P} 2$ & 8300 & 2800 & 1035 & 1005 & 738 & 18 & 170 & 161 & 19467 & 27 & - & 22 & 92 & 16 \\
\hline P3 & 11600 & 3250 & 1046 & 723 & - & 192780 & 185 & 162 & 19817 & 27 & - & 21 & 88 & 16 \\
\hline P4 & 9163 & 3185 & 911 & 734 & 564 & 183470 & 178 & 204 & 23093 & 31 & - & 24 & 100 & 23 \\
\hline P5 & 9093 & 2830 & 1228 & 541 & - & 16440 & 166 & 152 & 19253 & 23 & - & 24 & 92 & 15 \\
\hline P6 & 10320 & 2700 & 887 & 533 & - & 182343 & 162 & 153 & 18183 & 25 & - & 18 & 87 & 16 \\
\hline P7 & 10623 & 4813 & 1729 & 1548 & - & 183983 & 159 & 142 & 16920 & 25 & 40 & 23 & 79 & 25 \\
\hline P8 & 7010 & 3345 & 1092 & 2405 & - & 153290 & 163 & 162 & 19015 & 25 & - & 17 & 90 & 123 \\
\hline P9 & 12077 & 6780 & 825 & 793 & 542 & 176523 & 273 & 160 & 17507 & 21 & - & 22 & 82 & 40 \\
\hline P10 & 11220 & 6520 & 875 & 897 & 522 & 183067 & 302 & 216 & 26277 & 54 & - & 34 & 136 & 63 \\
\hline P11 & 9733 & 3750 & 2413 & 4407 & - & 194930 & 182 & 151 & 17470 & 25 & 72 & 26 & 88 & 24 \\
\hline P12 & 8153 & 3403 & 1859 & 501 & - & 160433 & 161 & 153 & 18567 & 26 & 122 & 19 & 86 & 107 \\
\hline P13 & 13493 & 4467 & 2387 & 4073 & - & 205073 & 167 & 137 & 16883 & 20 & - & 21 & 82 & 23 \\
\hline P14 & 9603 & 2820 & 998 & 571 & - & 192520 & 178 & 154 & 18887 & 26 & - & 26 & 90 & 18 \\
\hline P15 & 10033 & 3767 & 1618 & 1751 & - & 170803 & 171 & 150 & 18440 & 26 & - & 24 & 85 & 17 \\
\hline P16 & 9583 & 2910 & 903 & 485 & - & 175070 & 145 & 142 & 17497 & 24 & - & 26 & 87 & 18 \\
\hline P17 & 6770 & 2525 & 1382 & 662 & - & 136427 & 213 & 170 & 21277 & - & 151 & 24 & 101 & 20 \\
\hline P18 & 10310 & 3907 & 1290 & 1181 & - & 197657 & 187 & 160 & 19177 & 28 & - & 25 & 92 & 22 \\
\hline P19 & 10837 & 4957 & 1164 & 965 & - & 177000 & 173 & 165 & 19460 & 27 & - & 24 & 90 & 20 \\
\hline P20 & 10027 & 3223 & 1211 & 1349 & - & 172277 & 147 & 136 & 17177 & 25 & - & 25 & 83 & 15 \\
\hline P21 & 7953 & 3585 & 2080 & 660 & 577 & 159540 & 175 & 169 & 20193 & - & - & 27 & 101 & 112 \\
\hline P22 & 13177 & 4410 & 1862 & 3773 & 638 & 192483 & 216 & 162 & 19533 & 28 & - & 24 & 95 & 31 \\
\hline P23 & 9227 & 3633 & 2273 & 589 & - & 182463 & 160 & 160 & 18517 & 29 & - & 23 & 87 & 195 \\
\hline P24 & 11043 & - & 1294 & 1288 & 678 & 19490 & 153 & 152 & 18723 & 27 & - & 23 & 88 & 14 \\
\hline P25 & 11060 & 3880 & 2433 & 5737 & - & 160727 & 166 & 155 & 19230 & 32 & - & 30 & 92 & 24 \\
\hline P26 & 8590 & 3320 & 1570 & 973 & - & 161590 & 182 & 157 & 19537 & 32 & - & 24 & 95 & 140 \\
\hline P27 & 6027 & 2503 & 993 & 1705 & 491 & 114593 & 173 & 170 & 18320 & - & - & 36 & 95 & 37 \\
\hline
\end{tabular}

TABLE-4

ELEMENTAL CONCENTRATIONS OF TWENTY SEVEN ASHES OF PAPERS IN PARTS PER MILLION

\begin{tabular}{|c|c|c|c|c|c|c|c|c|c|c|c|c|}
\hline & $\mathrm{Mg}$ & $\mathrm{Al}$ & $\mathrm{Si}$ & $S$ & $\mathrm{Cl}$ & $\mathrm{Ca}$ & $\mathrm{Ti}$ & $\mathrm{Mn}$ & $\mathrm{Fe}$ & $\mathrm{Cu}$ & $\mathrm{Zn}$ & $\mathrm{Sr}$ \\
\hline $\mathrm{A} 1$ & 11417 & 31017 & - & 1286 & - & 421207 & - & 107 & 339 & 18 & - & 140 \\
\hline $\mathrm{A} 2$ & 14737 & 32567 & 9583 & - & - & 411310 & - & 97 & 323 & 22 & - & 138 \\
\hline A3 & 9103 & 35410 & 8245 & - & - & 432753 & - & 27 & 191 & 17 & - & 69 \\
\hline A4 & 7493 & 29353 & 7760 & 1642 & - & 440337 & - & 24 & 219 & 17 & 10 & 71 \\
\hline A5 & 10243 & 36530 & 9820 & 2350 & - & 413957 & - & - & 160 & 20 & - & 55 \\
\hline A6 & 9683 & 39967 & - & - & - & 406557 & - & 23 & 165 & 21 & - & 63 \\
\hline A7 & 9990 & 35971 & 17560 & 3150 & 1760 & 407930 & - & 35 & 805 & 21 & 13 & 168 \\
\hline A8 & 10660 & 36200 & 16203 & 2627 & 3163 & 420853 & - & 41 & 392 & 13 & 11 & 1314 \\
\hline A9 & 8943 & 37990 & 22443 & 1535 & 720 & 392663 & 252 & 54 & 700 & 19 & 14 & 334 \\
\hline A10 & 7917 & 18513 & 7870 & 1299 & 964 & 237987 & - & 29 & 216 & 32 & - & 120 \\
\hline A11 & 7960 & 31513 & 10403 & 3417 & 4560 & 387723 & - & 32 & 651 & 21 & - & 117 \\
\hline A12 & 8353 & 30710 & 12483 & 3193 & 801 & 402113 & - & 27 & 336 & 11 & - & 1056 \\
\hline A13 & 8893 & 34527 & 13533 & 2850 & 6210 & 377397 & 64 & 18 & 767 & 20 & - & 111 \\
\hline A14 & 6360 & 28380 & - & - & - & 404713 & - & 19 & 304 & 19 & - & 64 \\
\hline A15 & 8910 & 34930 & 14210 & 3470 & 1352 & 406250 & - & 24 & 413 & 22 & 13 & 87 \\
\hline A16 & 8830 & 34253 & 8565 & - & - & 426420 & - & 19 & 218 & 30 & 9 & 89 \\
\hline A17 & 13997 & 33543 & 9775 & 1947 & - & 42490 & - & 19 & 238 & 17 & - & 80 \\
\hline A18 & 9593 & 33287 & 13847 & 2240 & 1149 & 439923 & - & 38 & 434 & 20 & 12 & 118 \\
\hline A19 & 11657 & 40477 & 18510 & 2623 & 1057 & 427400 & - & 39 & 525 & 20 & 14 & 102 \\
\hline A20 & 7510 & 32950 & - & 2155 & 956 & 418013 & - & 19 & 193 & 14 & - & 69 \\
\hline A21 & 12673 & 37990 & 15943 & 4223 & 1003 & 434127 & - & 34 & 276 & 14 & 13 & 1124 \\
\hline A22 & 8317 & 36587 & 13260 & 3350 & 5043 & 406887 & 85 & 30 & 861 & 18 & 21 & 194 \\
\hline A23 & 6030 & 33017 & - & 1952 & 675 & 438593 & - & - & 154 & 13 & 9 & 62 \\
\hline A24 & 8060 & 31860 & 15187 & 3180 & 1494 & 418207 & - & 36 & 354 & 12 & 11 & 1864 \\
\hline A25 & 5753 & 35520 & 14130 & 3653 & 7567 & 399420 & - & 17 & 381 & 23 & 9 & 100 \\
\hline A26 & 10017 & 32580 & 15093 & 2677 & 1067 & 429527 & - & 24 & 410 & 10 & 9 & 1283 \\
\hline A27 & 15853 & 35430 & 16013 & 2837 & 1747 & 394563 & - & 92 & 376 & 32 & 15 & 332 \\
\hline
\end{tabular}




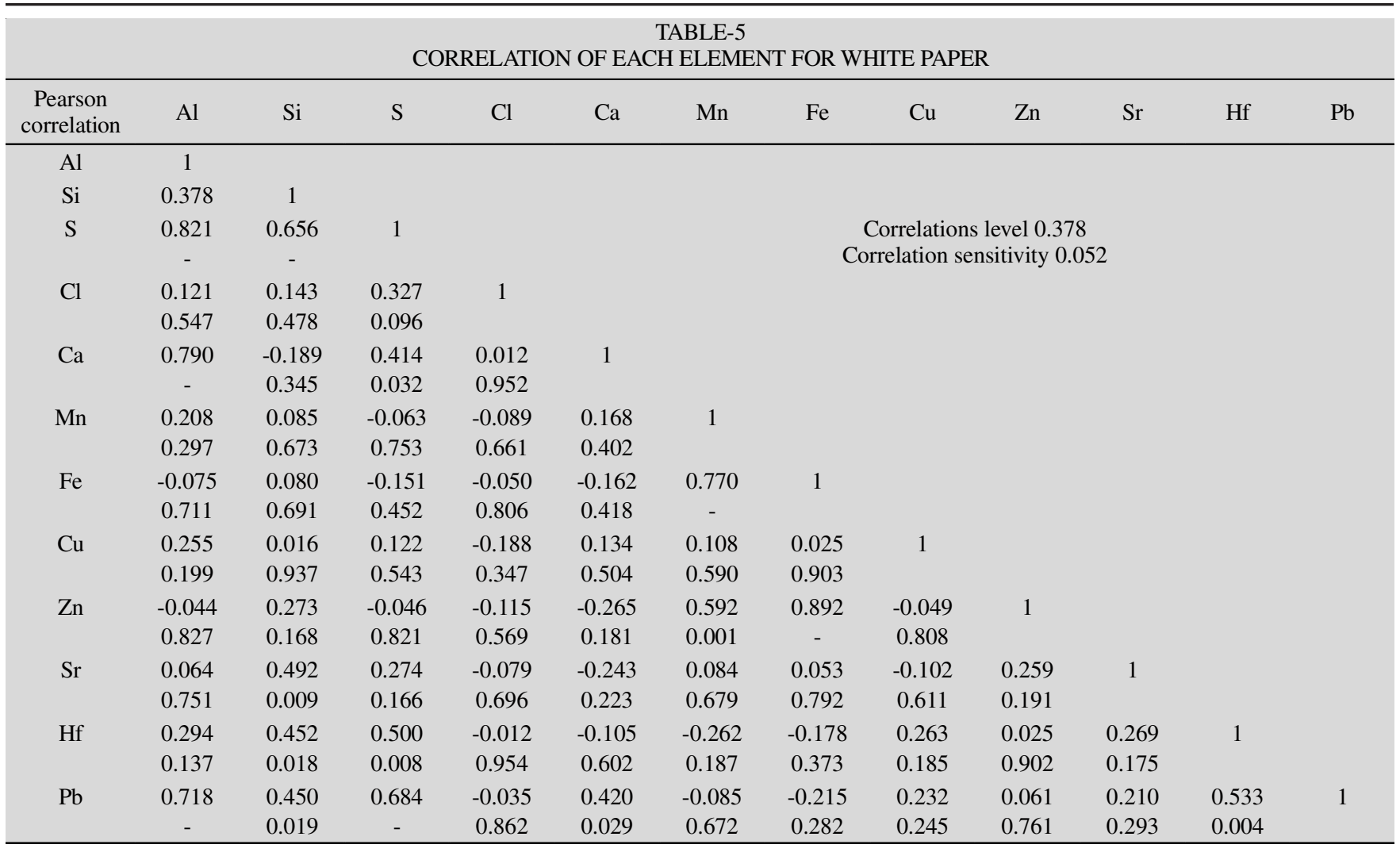

TABLE-6

CORRELATION OF EACH ELEMENT FOR THE PHOTOCOPIED PAPER

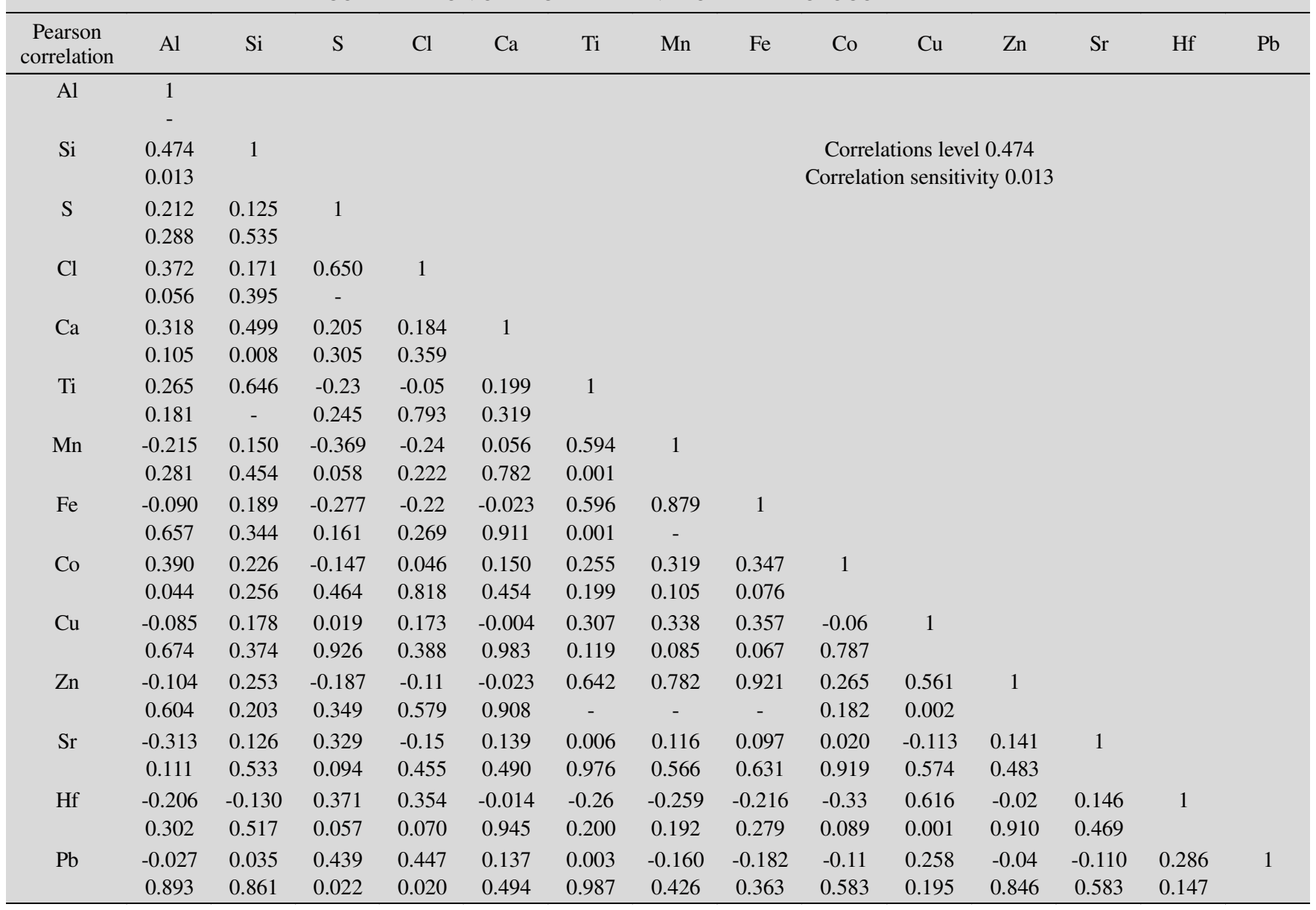


TABLE-7

CORRELATION OF EACH ELEMENT FOR THE ASHES OF PAPER

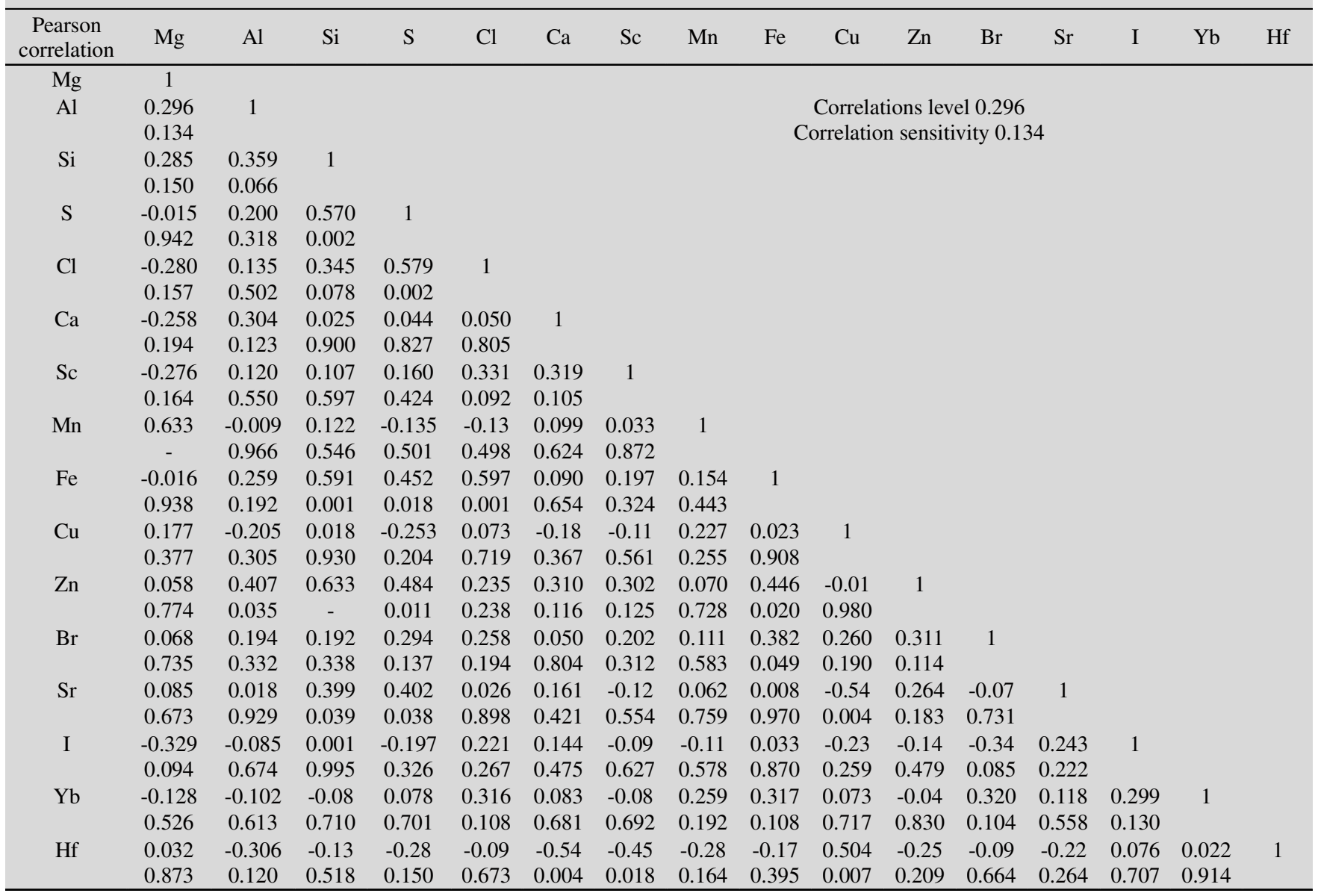

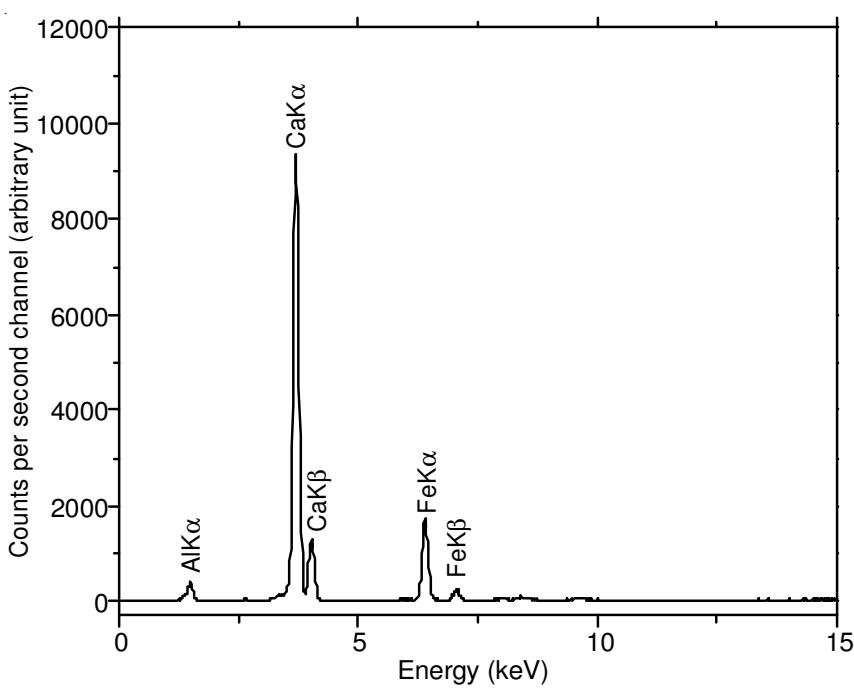

Fig. 5. EDXRF spectra of photocopied paper

Due to the lack of production standard of paper, many chemical elements, doped with different effects to the final properties of the produced paper, shall be added during its manufacturing. As the manufacturing process of paper is strictly protected by each manufacturer, it is difficult to say where certain elements come from but the researchers can deal with this problem as the identification of the content elements should be analyzed.

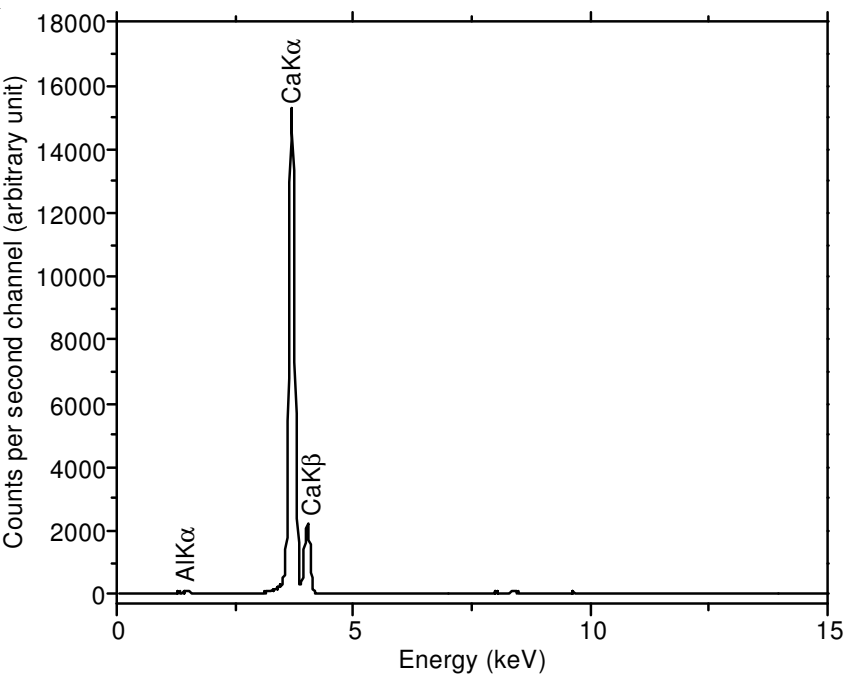

Fig. 6. EDXRF spectra of ashes of samples

Unlike white papers, manganese and titanium were detected on photocopied papers additionally, magnesium, scandium and strontium were determined on ashes of papers. It is thought that the contents of photocopied paper differ from the content of white paper because of the photocopying remnant. The content in ash samples is believed to be caused by the burning of papers.

The aim of this study is to compare the white paper, photocopied paper and ashes of paper in terms of elemental 
concentration. Besides, it is believed that the results obtained in this study will contribute to the data base on the paper elemental characterization.

Energy dispersive X-ray fluorescence analytical tool seems to be a good elemental analysis technique for analyzing the different types of the paper due to the advantage of being non-destructive.

\section{REFERENCES}

1. F. Cappitelli and C. Sorlini, Crit. Rev. Microbiol., 31, 1 (2005); https://doi.org/10.1080/10408410490884766.

2. M. Rozic, M.R. Macefat and V. Orescanin, Nucl. Instrum. Meth. B, 229, 117 (2005); https://doi.org/10.1016/j.nimb.2004.11.011.

3. G. Thompson, J. Swain, M. Kay and C.F. Forster, Bioresour. Technol., 77, 275 (2001); https://doi.org/10.1016/S0960-8524(00)00060-2.

4. A.M Springer, Industrial Environmental Control: Pulp and Paper Industry, Wiley-Interscience (1985).

5. M. Manso, S. Pessanha and M.L. Carvalho, Spectrochim. Acta B At. Spectrosc., 61, 922 (2006);

https://doi.org/10.1016/j.sab.2006.07.002.
6. J. Lartigue, T. Martinez, P. Avila-Perez, G. Zarazua and S. Tejeda, J. Radioanal. Nucl. Chem., 273, 759 (2007); https://doi.org/10.1007/s10967-007-0943-1.

7. M. Manso, M. Costa and M.L. Carvalho, Nucl. Instrum. Meth. B, 580, 732 (2007); https://doi.org/10.1016/j.nima.2007.05.136.

8. M. Manso, M. Costa and M.L. Carvalho, Appl. Phys. Mater, 90, 43 (2007); https://doi.org/10.1007/s00339-007-4235-y.

9. M. Manso, M. Costa and M.L. Carvalho, Spectrochim. Acta B At. Spectrosc., 63, 1320 (2008); https://doi.org/10.1016/j.sab.2008.07.001.

10. A. van Es, J. De Koeijer and G. van der Peijl, Sci. Justice, 49, 120 (2009); https://doi.org/10.1016/j.scijus.2009.03.006.

11. R.E. Nelson and T. Scarlett, GATF (1990); F.J. Romano and R.M. Romano, The GATF Encyclopedia of Graphic Communications, GATF Press, Pittsburgh, USA (1998); A. Swerin and L. Odberg, Das Papier, 50, 45 (1996).

12. J.L. Ferrero, C. Roldan, D. Juanes, J. Carballo, J. Pereira, M. Ardid, J.L. Lluch, and R. Vives, Nucl. Instrum. Meth. B, 213, 729 (2004); https://doi.org/10.1016/S0168-583X(03)01694-X.

13. M. Mantler and M. Schreiner, XRay Spectrom., 29, 3 (2000); https://doi.org/10.1002/(SICI) 1097-4539(200001/02)29:1<3::AIDXRS398>3.0.CO;2-O 